\title{
Checks, grids and tartans
}

\section{Chaoran Wang and Michael Andrew Hann ${ }^{\dagger}$}

University of Leeds International Textiles Archive, University of Leeds, UK

\begin{abstract}
Checks are best considered as a (visible) sub-set of grids, and each check consists of two assemblies of parallel lines, one superimposed on the other at ninety degrees. In the conventional textile context, one assembly of parallel yarns is superimposed on another at ninety degrees. These parallel lines caused by the yarns remain visually apparent in the finished composition. Commonly, checks are considered simply as a variety of woven textile and Scottish clan tartans, or plaids (common terminology for tartans in the USA), famously display a checked feature, using differently colored yarns in woven-textile form. Often the sequence of colours and the numbers of yarns used is equal in both warp and weft directions. Where this is the case, the tartan may be considered to be 'balanced' or 'regular', with the component yarns creating square units repeating across and down the fabric. Thus in balanced tartans, lengthways components have identical ordering, colouring and measured width to those used widthways. Meanwhile an unbalanced check lacks one or more of these attributes. This paper explores further the nature of Scottish clan tartans, using data collected from collections of rare tartans held at ULITA - An Archive of International Textiles at the University of Leeds.
\end{abstract}

Keywords: grid structure, checks, tartan, sett

\section{Introduction}

A woven check fabric is based on a simple grid form and consists of two assemblies of parallel yarns, one superimposed on the other at ninety degrees. These parallel yarns remain visually apparent in the finished composition. Scottish clan tartans display a checked feature, using yarns of different colours. This paper considers the nature of tartans, drawing on data collected from rare samples held at the University of Leeds. In the ICS publication Weaves, Fabrics, Textile Designing (1906, section 85, 12), a check was defined as " $\cdots$ the effect produced in a fabric by several bands or lines, usually, but not necessarily, of different colours, running in the direction of the warp and crossed at right angles by similar bands running in the $\cdots$ [weft-ways] direction".

It is proposed that checks are classified as 'balanced' or 'unbalanced'. Balanced checks have an equal number of types and colours of yarn in the same sequence and density in both weft and warp directions, whereas 'unbalanced' checks do not have these features. With respect to further classification, it seems appropriate simply to number the sequence of yarn types and colours and their density (e.g. the number per centimetre) in both weft and warp directions.

\section{The Nature of Scottish Clan Tartans}

Scottish clan tartans are a well-known category of

Received 22 July 2015, revised 25 August 2015, accepted 28 October 2015.

+ Corresponding author (M.A.Hann@leeds.ac.uk) 
checked textiles. Key publications include: Bain (1938), McClintock (1943), Innes (1945), Hesketh (1961), Dunbar (1962), Scarlett (1972 and 1973), Stewart (1974), Dunbar (1984), Teall and Smith (1992), Way and Squire (2000), Urquhart (2000 and 2005), Martine (2008), and Zaczek and Phillips (2009). Various tartan guide maps (with illustrations of tartan types and identification of geographical locations) have been produced over the years; a relatively recent example is the Tartan Map of Scotland (Collins, 2012).

\section{The Cloth Sett}

The 'cloth sett' (or simply 'sett') of a tartan gives the planned colour order and number of warp threads and weft threads per unit length (inch or centimetre). "The full sett is the sequence of colours read from right to left, turned about the pivot, and repeated left to right" (Urquhart, 2000, 14). The pivot point thus acts as a point of reflection symmetry (Fig. 1). Asymmetrical setts, on the other hand, "*..have no true pivots $\cdots$ The pattern is repeated from right to left across the width of the cloth" (Urquhart, 2000, 14). Examples of asymmetrical setts include the Buchanan and MacAlpine tartans (Stewart, 1974, 41 and 66). The vast majority of setts are, however, symmetrical and these appear largely the same when viewed across the cloth (horizontally, from right to left or left to right) and down the length of the cloth (vertically, from top to bottom or bottom to top); the direction of the twill lines will be different, however, depending on whether they are viewed horizontally or vertically, but in most cases this is only detectable at a close range of less than twenty centimetres and in some cases only at closer range with the assistance of magnification of the constituent woven structure.

Examples of setts (including colourings and yarn numbers) have been highlighted in past publications (e.g. ICS, 1906, section 85, 24-26; Stewart, 1974, 31-111). In many cases the colouring extends over a surprisingly large number of threads. Examples include the Royal Stuart (184 threads), Gordon (418 threads), Blackwatch (184 threads), MacGowan (292 threads), MacPherson (182 threads) and Campbell of Breadalbane (244 threads) (ICS, section 85, 25-26). Campbell of Argyle requires 164 threads for each component repeat (in both warp and weft directions); the colouring has been listed as follows: 26 dark green, 2 black, 4 yellow, 2 black, 26 dark green, 26 black, 24 dark blue, 4 white, 24 dark blue and 26 black (ICS, section $85,24)$. The following contractions/abbreviations are in common usage among weavers, to express the sequence of colours used in traditional tartans: 'Bk (Black); B (Dark Blue); P (Purple); LB or AZ (Light Blue, Azure); G (Dark Green); LG (Light Green); R (Scarlet); Cr (Crimson); Y (yellow); W (White); Gy
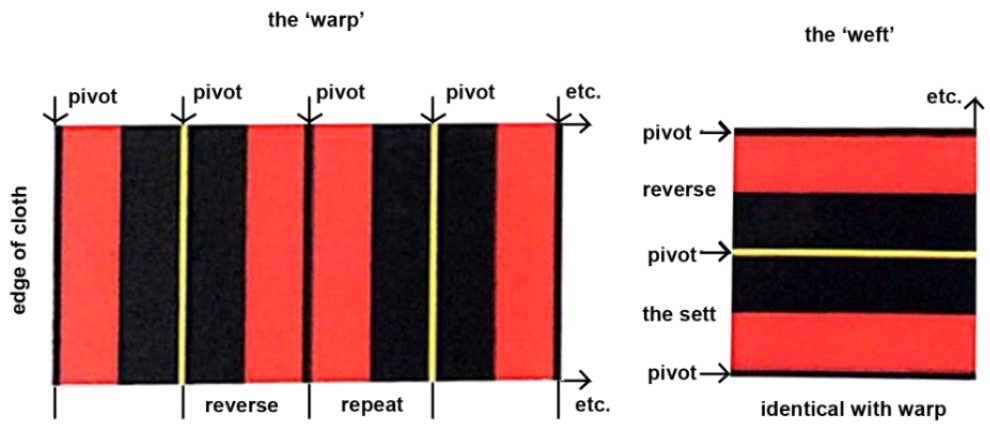

the tartan

〈Fig. 1〉 Example of Scottish tartan construction showing pivot points

From. Shin, 2011, 128 
(Grey). Other colours are named' (Stewart, 1974, 33). Data from a selection of twenty-five tartan setts were collected from various key publications and also from a rare collection of samples held at ULITA - An Archive of International Textiles (University of Leeds).

\section{Tartan Sett Analysis}

From the data collected, it is remarkable, when reviewing the order and numbers of coloured threads in the 258 sett examples given by Stewart (1974), that the vast majority of numbers presented are even numbers, with a seeming predominance of numbers $2,4,6,8,16,24$ and 32. Such numbering appears to be the convention across all post-Industrial-Revolution preparatory-weaving processes as well as in the weaving process itself. The relationship between $2 / 2$ twill weaving, and check production is illustrated in $\langle$ Fig. 2$\rangle$.

In this research, a selection of twenty-five Scottish

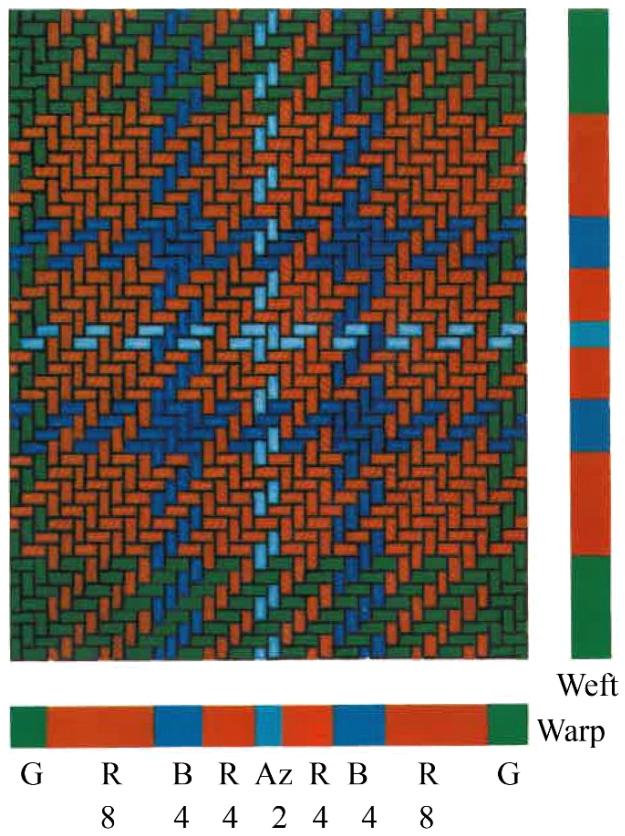

〈Fig. 2〉 The relationship between $2 / 2$ twill weaving, colour-strip and thread-count From. Stewart, 1974, 41 tartans, from collections of rare tartans held at ULITA - An Archive of International Textiles at the University of Leeds were analysed. Reflection symmetry and check proportions were calculated in each case. Reference was made also to examples given in the book 'The Setts of the Scottish Tartans' (Stewart, 1974). The selected samples and their sett numbers are listed in $\langle$ Table 1$\rangle$. It is observed from $\langle$ Table 1$\rangle$, that the majority of the number setts is asymmetrical, which means, in most of the cases, the two numbers on the two ends are pivotal strips in the process of weaving.

The setts numbers in Davidson (No. 4): 2, 12, 6, 12, 2, Macpherson: Clan and Hunting (No. 17): 2, 2 , 16, 2, 2, 2, 16, 2, 2 and Montgomerie (No. 19): 8, 10, $8,56,8,10,8$ appear to show reflection symmetry with the reflection axis in the middle of the sett number, so that these tartans have one more reflection axis apart from the two pivotal points. The numbers of the pivotal strips (or reflection axis) are shown in $\langle$ Table 1$\rangle$.

Furthermore, by actually measuring the widths of the overlapping checks out of those samples, it is obvious that some proportions are shown frequently. The measurements data and the calculated proportions are listed in $\langle$ Table 2$\rangle$. The most common proportion found is 1:2, in 18 out of 25 of the selected samples, followed by the proportion of $1: 3$, which appears 14 times. The proportion of $2: 3$ is found 12 times, followed by the proportions of $3: 5$ and $2: 5$, which exist in 11 and 7 samples respectively. Most of these proportions are also commonly used in other design disciplines.

\section{Conclusion}

Woven checks show groups of coloured yarns repeating systematically in weft and warp directions. Often checks are regarded as 'balanced', with equally spaced numbers, types and colours of yarns in both weft and warp directions. Tartans are the best-known 
〈Table 1〉 Name, setts and number of pivotal points of selected tartans

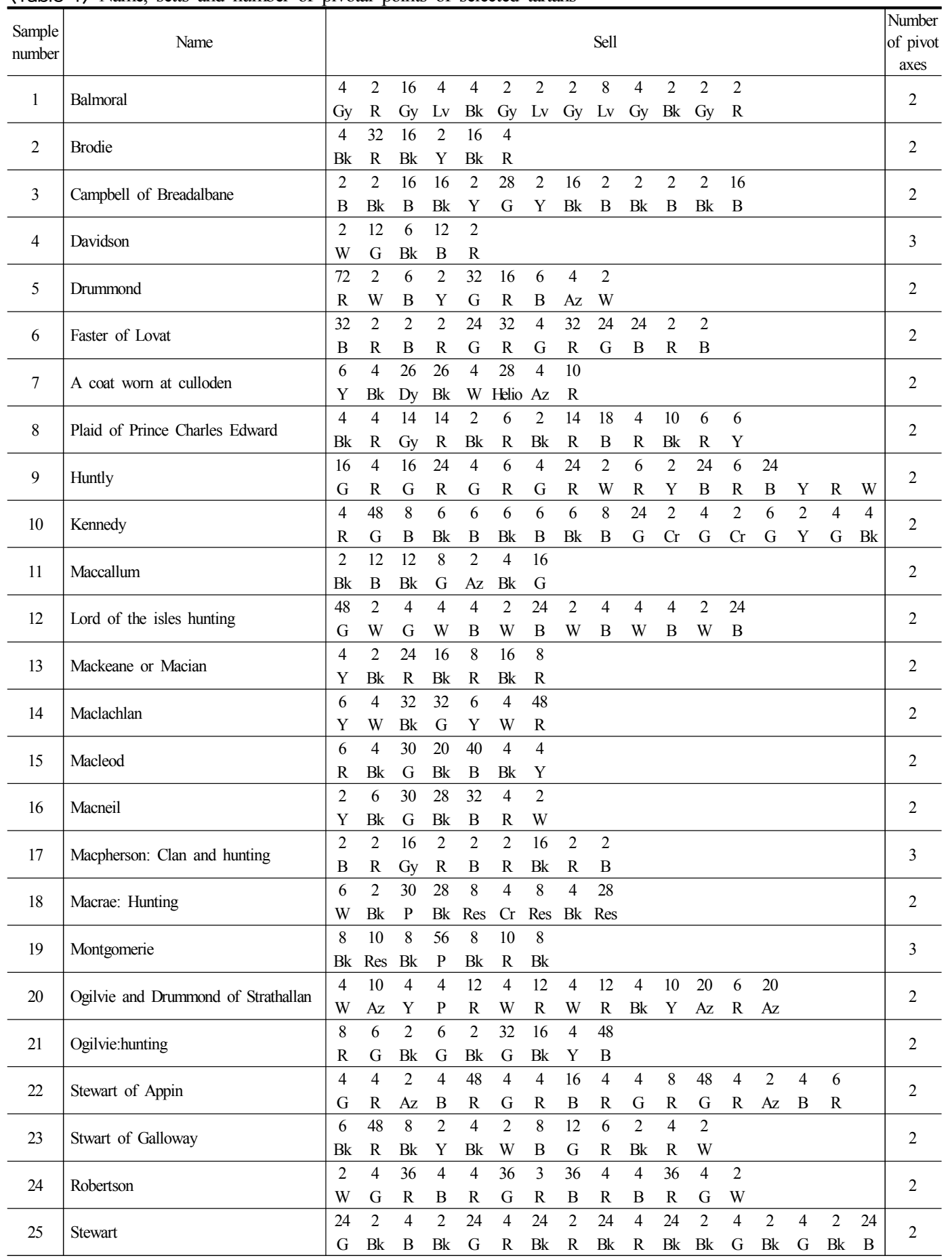

Source: Stewart, D. C. (1974). The Setts of the Scottish Tartans, London: Shepheard-Walwyn.

Keys: Number in pivots given (in column 4) is in each direction (Warp and Weft)

$\mathrm{Y}=$ Yellow; $\mathrm{R}=$ Red; $\mathrm{B}=\mathrm{Blue} ; \mathrm{Bk}=$ Black; $\mathrm{Gy}=\mathrm{Grey} ; \mathrm{G}=\mathrm{Green}$; $\mathrm{W}=$ white, etc. 
〈Table 2〉 Name, numbers in sett and proportions in sett

\begin{tabular}{|c|c|c|c|}
\hline $\begin{array}{l}\text { Sample } \\
\text { number }\end{array}$ & Name & Numbers in sett & Proportions in sett \\
\hline 1 & Balmoral & $\begin{array}{llll}2 & 4 & 8 & 16 \\
\end{array}$ & 1:02 $1: 04$ \\
\hline 2 & Brodie & 241632 & $\begin{array}{llll}1: 02 & 1: 04 & 1: 08 & 1: 16 \\
\end{array}$ \\
\hline 3 & Campbell of Breadalbane & 21628 & 1:09 1:14 4;07 \\
\hline 4 & Davidson & $\begin{array}{lll}2 & 6 & 12\end{array}$ & 1:02 $\quad 1: 03 \quad 1: 06$ \\
\hline 5 & Drummond & $\begin{array}{llllll}2 & 4 & 6 & 16 & 32 & 72\end{array}$ & $\begin{array}{lllllllllll}1: 02 & 1: 03 & 1: 04 & 1: 08 & 1: 12 & 1: 16 & 1: 18 & 2: 09 & 3: 08 & 3: 16 & 6: 16\end{array}$ \\
\hline 6 & Faster of Lovat & 242432 & $1: 12 \quad 1: 16 \quad 3: 04$ \\
\hline 7 & A coat worn at culloden & $\begin{array}{llll}4 & 6 & 10 & 2628 \\
\end{array}$ & $\begin{array}{llllllll}2: 03 & 2: 05 & 2: 13 & 1: 07 & 5: 13 & 5: 14 & 13: 14\end{array}$ \\
\hline 8 & Plaid of Prince Charles Edward & $\begin{array}{llllll}2 & 4 & 6 & 10 & 14 & 18\end{array}$ & $\begin{array}{llllllllllllll}1: 02 & 1: 03 & 1: 05 & 1: 07 & 1: 09 & 2: 03 & 2: 05 & 2: 07 & 2: 09 & 3: 05 & 3: 07 & 5: 07 & 5: 09 & 7\end{array}$ \\
\hline 9 & Huntly & $2 \quad 4 \quad 6 \quad 1624$ & $\begin{array}{lllllllllll}1: 02 & 1: 03 & 1: 04 & 1: 06 & 1: 08 & 1: 12 & 2: 03 & 3: 08\end{array}$ \\
\hline 10 & Kennedy & $\begin{array}{llllll}2 & 4 & 6 & 8 & 24 & 48 \\
\end{array}$ & $\begin{array}{llllllllll} & 1: 02 & 1: 03 & 1: 04 & 1: 06 & 1: 08 & 1: 12 & 1: 24 & 2: 03 & 3: 04 \\
\end{array}$ \\
\hline 11 & Maccallum & $\begin{array}{lllll}2 & 4 & 8 & 12 & 16 \\
\end{array}$ & $\begin{array}{llllllllll}1: 02 & 1: 03 & 1: 04 & 1: 06 & 1: 08 & 2: 03 & 3: 04\end{array}$ \\
\hline 12 & Lord of the isles hunting & 242448 & 1:02 $1: 06 \quad 1: 12 \quad 1: 24$ \\
\hline 13 & Mackeane or Macian & $24 \quad 8 \quad 1624$ & $\begin{array}{lllllllllllll}1: 02 & 1: 03 & 1: 04 & 1: 06 & 1: 08 & 1: 12 & 2: 03 \\
\end{array}$ \\
\hline 14 & Maclachlan & $4 \quad 6 \quad 3248$ & 1:08 $1: 12 \quad 2: 03 \quad 3: 16$ \\
\hline 15 & Macleod & $4 \quad 6 \quad 203040$ & 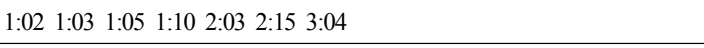 \\
\hline 16 & Macneil & $2 \quad 4 \quad 6 \quad 283032$ & $\begin{array}{lllllllllllllllll}: 02 & 1: 03 & 1: 05 & 1: 07 & 1: 08 & 1: 15 & 1: 16 & 2: 03 & 2: 15 & 3: 14 & 3: 16 & 4: 15 & 5: 16 \\
\end{array}$ \\
\hline 17 & Macpherson: Clan and hunting & 216 & 1:08 \\
\hline 18 & Macrae: Hunting & $\begin{array}{llllll}2 & 4 & 6 & 8 & 28 & 30\end{array}$ & 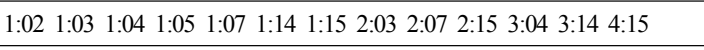 \\
\hline 19 & Montgomerie & 81056 & 4:05 5:07 5:28 \\
\hline 20 & Ogilvie and Drummond of Strathallan & $\begin{array}{lllll}4 & 6 & 10 & 12 & 20\end{array}$ & $\begin{array}{llllllllll}1: 02 & 1: 03 & 1: 05 & 2: 03 & 2: 05 & 3: 05 & 3: 10 & 5: 06\end{array}$ \\
\hline 21 & Ogilvie:hunting & \begin{tabular}{lllllll|}
2 & 4 & 6 & 8 & 16 & 32 & 48 \\
\end{tabular} & 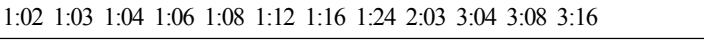 \\
\hline 22 & Stewart of Appin & $\begin{array}{llllll}2 & 4 & 6 & 8 & 16 & 48\end{array}$ & $\begin{array}{lllllllllll}1: 02 & 1: 03 & 1: 04 & 1: 06 & 1: 08 & 1: 12 & 1: 24 & 2: 03 & 3: 04 & 3: 08\end{array}$ \\
\hline 23 & Stwart of Galloway & $\begin{array}{llllll}2 & 4 & 6 & 8 & 12 & 48\end{array}$ & $\begin{array}{llllllllll}1: 02 & 1: 03 & 1: 04 & 1: 06 & 1: 08 & 1: 12 & 1: 14 & 2: 03 & 3: 04\end{array}$ \\
\hline 24 & Robertson & $23 \quad 4 \quad 36$ & 1:02 $1: 09 \quad 1: 18$ \\
\hline 25 & Stewart & 2424 & 1:02 $1: 06 \quad 1: 12$ \\
\hline
\end{tabular}

variety of woven checks. It is remarkable, when reviewing the order and numbers of coloured threads in the 258 setts presented by Stewart (1974, 37-111), that numbers presented are even numbers, with a seeming predominance of numbers 2, 4, 6, 8, 16, 24 and 32. This predominance of even thread numbers in checked textiles of various kinds allows the weaver to ensure commensurable stripe widths in warp and weft directions. Assuming a square sett, the resultant dimensions of the overlapping squares in the finished cloth will be commensurable with each other. Commensurable, overlapping squares are therefore a feature across the majority of tartan types. Most tartans are designed in a symmetrical way, and often the two end numbers of a sett are the pivotal points which act as reflection axes in the weaving process. A small number of them (three out of twenty-five in the samples selected) appear to have more than 2 reflection axes. Furthermore the most common proportions used in tartans are: 1:2, 1:3, 2:3 3:5 and 2:5, proportions found readily in other design areas.

\section{References}

Bain, R. (1938). The Clans and tartans of Scotland. London and Glasgow: Collins.

Dunbar, J. T. (1962). The history of Highland dress. Edinburgh: Oliver and Boyd. 
Dunbar, J. T. (1984). The costume of Scotland. London: Batsford.

Hesketh, C. (1961). Tartans. London: Weidenfeld and Nicholson.

ICS (1906). Weaves, fabrics, textile designing. In ICS Reference Library (Series Ed.). Scranton, PA: International Textbook Company for International Correspondence School.

Innes (of Learney), T. (1945). The tartans of the Clans and families of Scotland. Edinburgh and London: W. \& A. K. Johnston Ltd.

Martine, R. (2008). Scottish Clan and family names: Their arms, origins and tartans (Rev. ed.). Edinburgh: Mainstream Publishing.

McClintock, H. F. (1943). Old Irish and Highland dress. Dundalk: W. Tempest.

Scarlett, J. D. (1972). Tartans of Scotland. London: Lutterworth Press.

Scarlett, J. D. (1973). The tartan spotter's guide. London: Shepheard-Walwyn.
Stewart, D. C. (1974). The setts of the Scottish tartans. London: Shepheard-Walwyn.

Stewart, D. W. (1893). Old and rare scottish tartans. Edinburgh: George P. Johnston.

Teall, G., \& Smith, P. (1992). District tartans. London: Shepheard-Walwyn.

Urquhart, B. (2000). Tartans: The illustrated identifier to over 140 designs. London: Apple Press.

Way, G., \& Squire, R. (Eds) (2000). Clans and tartans. Glasgow: Harper Collins.

Zaczek, I., \& Phillips, C. (2009). The complete book of tartan: A heritage encyclopaedia of over 400 tartans and stories that Shaped Scottish history. London: Lorenz Books (with Anness Publishing).

Note: Some of the text presented above is a summarised version of material presented in the forthcoming book: Stripes, Grids and Checks (Bloomsbury, London and New York, anticipated 2015). 